\title{
TENSION MECHANISM DYNAMIC ANALYSIS
}

The aim of the presented article is to show how to create a mathematical model of the tension mechanism working by a spring motion generation and contacting a rigid body at the end of the motion.

Keywords: Mechanism, analysis, contact force, simulation.

\section{Introduction}

The first step of the above described task solution was the creation of the mechanism mathematical model assembled from three movable parts and the motion generating spring (Fig. 1).

The second step was the analysis of the forces applied on the mechanism during the workflow.

\section{Mechanism Modeling}

The mechanism movement is generated by a spring affecting the sliding joint between the mechanism parts labeled 2 and 3 (Fig. 1).

The main problem of the analysis is the moment when the mechanism reaches its end position and contacts the frame rigid body with the part 1 (Fig. 1) because of the contact properties of the contact point.
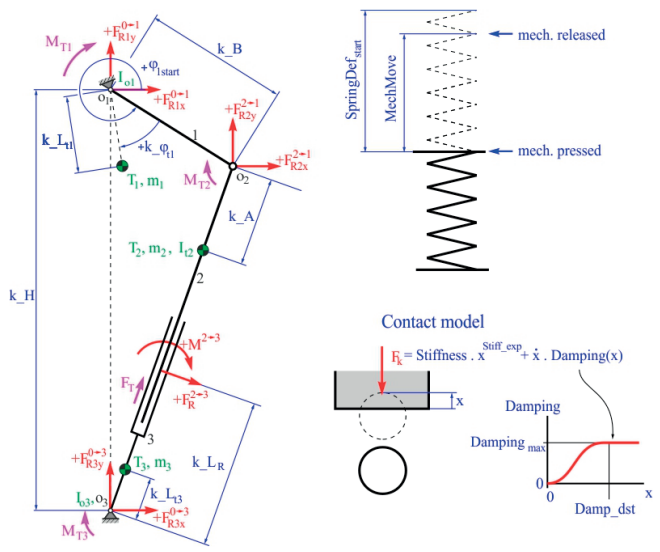

Fig. 1 Model of the mechanism structure including the spring and contact model (Source: authors)

\subsection{Dimensions and spring parameters}

The kinematics of the mechanism parts parameters were defined according to the $3 \mathrm{D}$ model and Table 1.

Dimensions and spring parameters of the mechanism

Table 1

\begin{tabular}{|l|c|c|c|}
\hline Name & Label & Value & Unit \\
\hline Part 1 length & k_B & 0.05 & $\mathrm{~m}$ \\
\hline $\begin{array}{l}\text { Part 1 centre of gravity } \\
\text { distance }\end{array}$ & $\mathrm{k}_{\text {_ }} \mathrm{t}$ 1 & 0.02 & $\mathrm{~m}$ \\
\hline $\begin{array}{l}\text { Part 1 angle of the } \\
\text { centre of gravity }\end{array}$ & $\mathrm{k} \_\phi_{\mathrm{t} 1}$ & $\pi / 4$ & $\mathrm{rad}$ \\
\hline $\begin{array}{l}\text { Part 2 centre of gravity } \\
\text { distance }\end{array}$ & $\mathrm{k} \_\mathrm{A}$ & 0.03 & $\mathrm{~m}$ \\
\hline $\begin{array}{l}\text { Part 3 centre of gravity } \\
\text { distance }\end{array}$ & $\mathrm{k} \_\mathrm{L}$ t3 & 0.02 & $\mathrm{~m}$ \\
\hline $\begin{array}{l}\text { Distance of revolution } \\
\text { joints O1 and O3 }\end{array}$ & k_H & 0.1 & $\mathrm{~m}$ \\
\hline Spring stiffness & SpringStiffnes & 1000 & $\mathrm{~N} . \mathrm{m}^{-1}$ \\
\hline Spring working stroke & MechMove & 0.03 & $\mathrm{~m}$ \\
\hline $\begin{array}{l}\text { Starting spring } \\
\text { deformation }\end{array}$ & SpringDefstart & 0.1 & $\mathrm{~m}$ \\
\hline
\end{tabular}

The initial values of the mechanism parameters are defined in Table 2.

Initial values of the mechanism parameters

Table 2

\begin{tabular}{|l|c|c|c|}
\hline Name & Label & Value & Unit \\
\hline Part 1 initial angle of the centre of gravity & $\varphi_{1 \text { start }}$ & $-\pi / 4$ & $\mathrm{rad}$ \\
\hline Part 2 initial variable distance & $\mathrm{k}_{-} \mathrm{L}_{\mathrm{R}}$ & 0 & $\mathrm{~m}$ \\
\hline
\end{tabular}

The angle by the full pressed mechanism is defined as $\varphi_{1 \text { start }}$. The reaction force position $k_{-} L_{R}$ influences only the moment value $M$.

\footnotetext{
* ${ }^{1}$ Michal Lukac, ${ }^{1}$ Frantisek Brumercik, ${ }^{1}$ Leszek Krzywonos, ${ }^{2}$ Pawel Drozdziel ${ }^{1}$ Faculty of Mechanical Engineering University of Zilina, Slovakia

${ }^{2}$ Mechanical Engineering Faculty, Lublin University of technology, Poland E-mail: michal.lukac@fstroj.uniza.sk
} 
The motion generating spring positions are defined in Fig. 2.
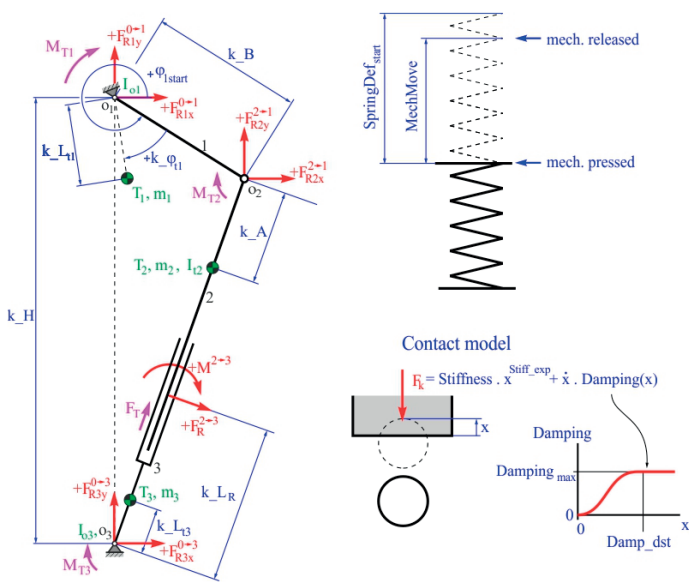

Fig. 2 Spring positions (Source: authors)

\subsection{Mass properties}

The mechanism mass properties are defined according to the 3D model and its calculation model (Fig. 1) in Table 3.

Mass properties parameters of the mechanism

Table 3

\begin{tabular}{|l|c|c|c|}
\hline Name & Label & Value & Unit \\
\hline Part 1 mass & $\mathrm{m}_{1}$ & 59.238 & $\mathrm{~kg}$ \\
\hline Part 1 inertia & $\mathrm{I}_{\mathrm{o}}$ & $2.843445 .10^{-2}$ & $\mathrm{~kg} \cdot \mathrm{m}^{2}$ \\
\hline Part 2 mass & $\mathrm{m}_{2}$ & 0.5 & $\mathrm{~kg}$ \\
\hline Part 2 inertia & $\mathrm{I}_{02}$ & 0.1 & $\mathrm{~kg} \cdot \mathrm{m}^{2}$ \\
\hline Part 3 mass & $\mathrm{m}_{3}$ & 25.574 & $\mathrm{~kg}$ \\
\hline Part 3 inertia & $\mathrm{I}_{03}$ & $1.13983182 .10^{-2}$ & $\mathrm{~kg} \cdot \mathrm{m}^{2}$ \\
\hline
\end{tabular}

\subsection{Friction and contact properties}

The developed simulation program in the chosen software (Mathcad) allows to activate the friction via the created "Friction" GUI button. Contact properties of the mechanism are defined according to the 3D model in Table 4 .

Contact properties parameters of the mechanism
\begin{tabular}{|l|c|c|c|}
\hline Name & Label & Value & Unit \\
\hline Mechanism stiffness & Stiffnes & 200000 & N.m.1 \\
\hline Stiffness exponent & Stiff_exp & $2(>=1)$ & N.m \\
\hline $\begin{array}{l}\text { Mechanism maximum damping } \\
\text { factor }\end{array}$ & Dampingmax & 500 & N.m ${ }^{-1} \cdot \mathrm{s}$ \\
\hline $\begin{array}{l}\text { Distance to max. damping } \\
\text { build-up }\end{array}$ & Damp_dst & 0.002 & $\mathrm{~m}$ \\
\hline Joint O1 friction moment & $\mathrm{M}_{\mathrm{T} 1}$ & 0.5 & $\mathrm{~N} \cdot \mathrm{m}$ \\
\hline Joint O1 friction factor & $\mathrm{k}_{\mathrm{MT} 1}$ & 0 & - \\
\hline Joint O2 friction moment & $\mathrm{M}_{\mathrm{T} 2}$ & 1 & $\mathrm{~N} \cdot \mathrm{m}$ \\
\hline Joint O2 friction factor & $\mathrm{k}_{\mathrm{MT} 2}$ & 0 & - \\
\hline Joint O3 friction moment & $\mathrm{M}_{\mathrm{T} 3}$ & 1 & $\mathrm{~N} \cdot \mathrm{m}$ \\
\hline Joint O3 friction factor & $\mathrm{k}_{\mathrm{MT} 3}$ & 0 & - \\
\hline
\end{tabular}

The $\mathrm{k}_{\mathrm{MT1}, 2,3}\left(\operatorname{rad} . \mathrm{s}^{-1}\right)$ and $\mathrm{k}_{\mathrm{FT}}\left(\mathrm{m} . \mathrm{s}^{-1}\right)$ values are considered by the friction button turned to ON. The direction of the friction force (moment) depends on the motion direction (from the motion parts relative velocity sign). If the velocity is too slow, its direction can vary and so can also the direction of the friction force. Therefore, the friction force value is defined to rise around zero velocity to maximum [1] and [2].

The described k-value defines the velocity interval of the maximum friction force. The principle of the calculation is similar to the contact model damping calculation (the value is equivalent to the Damp_dst value). The k-value is different for every friction force because every friction couple velocity varies. The lower is the $\mathrm{k}$-value, the more accurate is the calculation. If the model does not work in the friction mode, the solution is to raise the k-value which is usually $1.10^{-3}$ and lower [3]. The k-value does not affect the calculation without the friction consideration. The start of the simulation has to be done with the zero value and the solver type FIXED (parameters for the Mathcad software).

There is also the fon_step function defined because of the smooth transition between two values of the damping coefficient in the contact point. This leads to smooth rise of this coefficient without the step rise to the maximum in the contact moment.

The value of the damping rises during the defined penetration depth Damp_dst. and then becomes stabillized to "Damping max" value (Table 4, Fig. 3). 

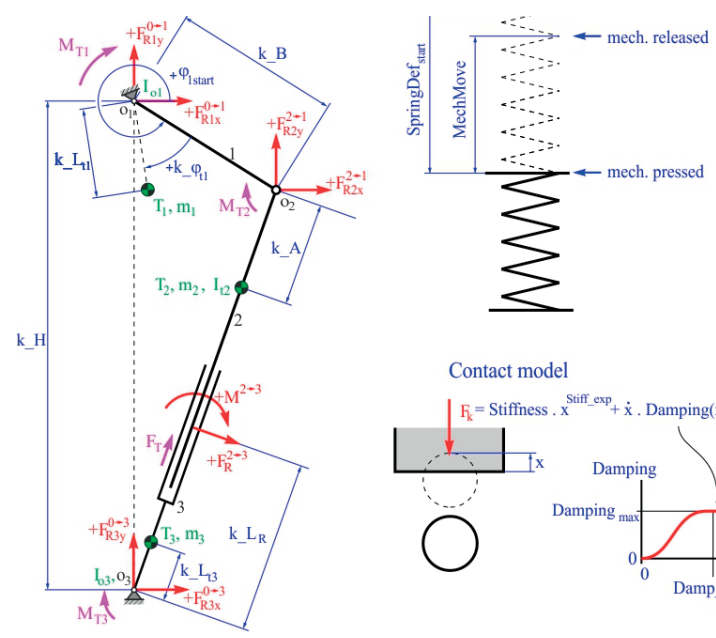

Contact model

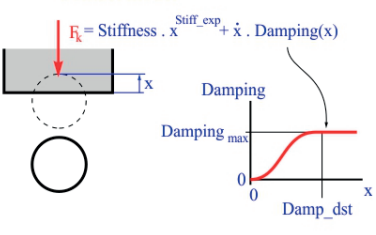

Fig. 3 Contact model (Source: authors)

\section{Solver parameters}

The solver parameters were defined as follows in Table 5.

Solver parameters

Table 5

\begin{tabular}{|l|c|c|c|}
\hline Name & Label & Value & Unit \\
\hline Time interval $\left(0-\mathrm{t}_{\text {end }}\right)$ & $\mathrm{t}_{\text {count }}$ & 1000 & - \\
\hline $\begin{array}{l}\text { Number of the points in the } \\
\text { plotted graphs }\end{array}$ & $\mathrm{N}_{\mathrm{t}}$ & 1001 & - \\
\hline End time of the simulation & $\mathrm{t}_{\text {end }}$ & 1 & $\mathrm{~S}$ \\
\hline Friction force & $\mathrm{F}_{\mathrm{T}}$ & 10 & $\mathrm{~N}$ \\
\hline Friction force factor & $\mathrm{k}_{\mathrm{FT}}$ & 0 & - \\
\hline
\end{tabular}

The larger is the number of the time interval $\left(0-\mathrm{t}_{\text {end }}\right)$ division during the simulation, the more accurate is the calculation. If the calculation does not converge, new solver has to be used (right button on the odesolve function in the MathCad) [4].

\section{Interpolation of bodies coordinates}

The bodies coordinates that are interesting for the interpolation during simulation are labeled $\varphi_{2}$ and $\mathrm{L}_{\mathrm{t} 2}$ in Fig. 4. The parameters influencing the interpolation are defined in Table 6.

Interpolation influencing parameters

Table 6

\begin{tabular}{|l|c|c|c|}
\hline Name & Label & Value & Unit \\
\hline Control variable & CTOL & 0.00001 & - \\
\hline Control variable & TOL & 0.00001 & - \\
\hline Polynomial degree & FitDegree & 7 & - \\
\hline Number of points & NuPo & 200 & - \\
\hline
\end{tabular}

The Mathcad TOL worksheet variable controls the precision to which integrals and derivatives are evaluated. TOL also controls convergence criteria in Solve Blocks and in the root function. The two most recent estimates of a solution must differ by less than the built-in variable TOL. The CTOL worksheet variable controls how closely a constraint in a Solve Block must be met for a solution to be acceptable. It is used by optimizing functions like: Minimize, Maximize, Find, or Minerr. For example, a constraint such as $\mathrm{x}<2$ must be satisfied to within CTOL before a solution is returned. If CTOL $=0.001$ (the default), this constraint is satisfied if $x<2.001$ [5] and [6].

Figure 4 shows the simplified view of the mechanism with all important variables and their first and second derivatives.

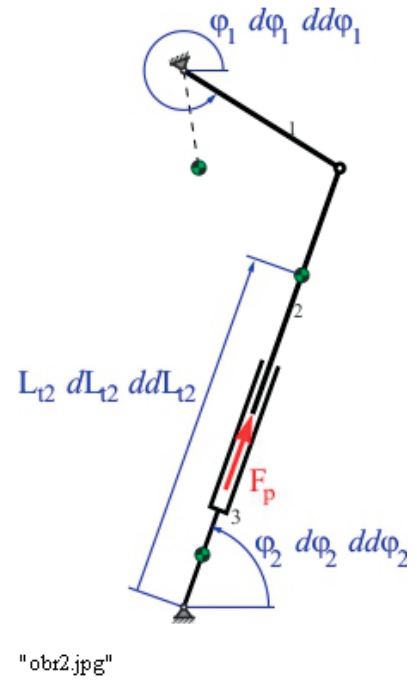

Fig. 4 Simplified view of important mechanism variables

(Source: authors)

The calculated mechanism has one degree of freedom (DOF). All forces and masses are reduced to the mechanism part 1 coordinate $\varphi_{1}$.

It is necessary to define the coordinates $\mathrm{L}_{\mathrm{t} 2}$ and $\varphi_{2}$ as a function of the $\varphi_{1}$ coordinate. To make the calculation effective and simple, the coordinates $\mathrm{L}_{\mathrm{t} 2}$ and $\varphi_{2}$ are defined as a function of the $\varphi_{1}$ by the interpolation polynomial of the 7-th degree! The FitDegree value has to remain defined to 7 during the calculation because all equations are derived for this polynomial degree [7].

The R_disp function displays the $\mathrm{L}_{\mathrm{t} 2}$ and $\varphi_{2}$ coordinate values depending upon $\varphi_{1}$ for the $\varphi_{1}$ values from $-\pi / 2$ to $\pi / 2$. In this interval, the mechanism is resolvable - the values outside the interval will not be calculated correctly.

The number of values labeled NuPo specifies the calculation of the interpolation polynomial coefficients for the $\varphi_{2}$ and $\mathrm{L}_{\mathrm{t} 2}$ coordinates. The Disp_Coeff software feature displays the polynomial coefficients. The angle of the $\varphi_{1}$ coordinate between the threshold limit $-\pi / 2$ and $\pi / 2$ is defined as ff 1 . 

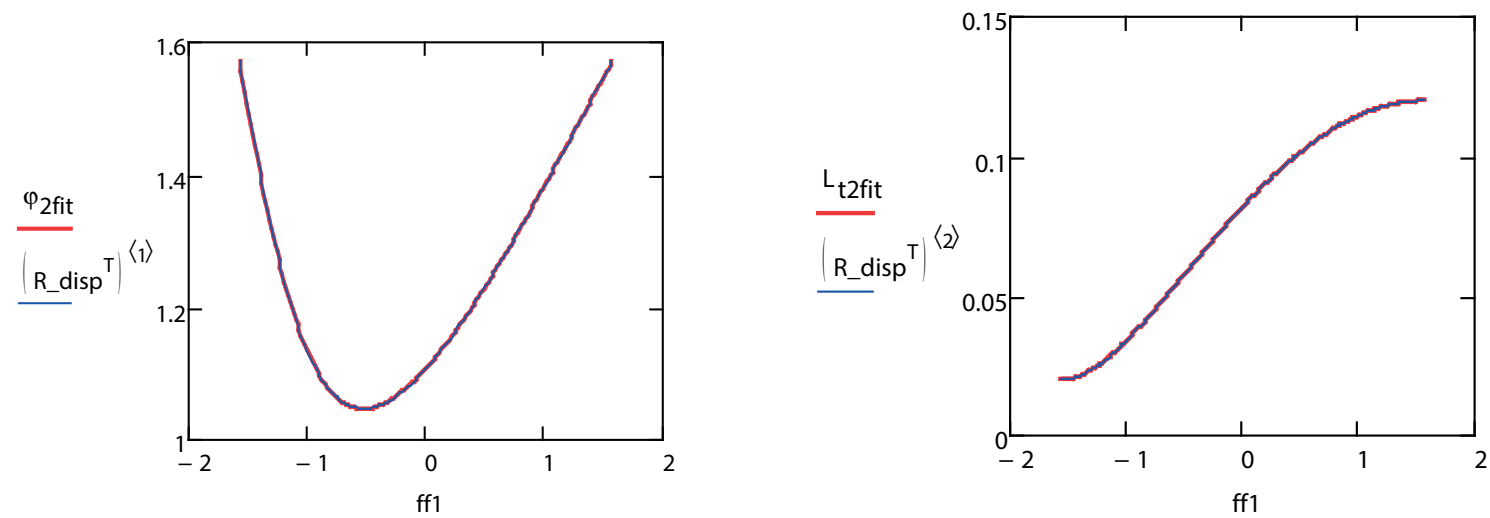

Fig. 5 Interpolated and calculated data match test of the mechanism variables (Source: authors)

The equations representing the relationships between the coordinates are following:

$\mathrm{L}_{\mathrm{t} 2} \cdot \cos \left(\varphi_{2}\right)+\mathrm{kA} \cdot \cos \left(\varphi_{2}\right)+\mathrm{kB} \cdot \cos (\varphi 1-\pi)=0$ $\mathrm{L}_{\mathrm{t} 2} \cdot \sin \left(\varphi_{2}\right)+\mathrm{kA} \cdot \sin \left(\varphi_{2}\right)+\mathrm{kB} \cdot \sin (\varphi 1-\pi)$

$-\mathrm{kH}=0$

The comparison between the interpolated data (red) and real data (blue) for the angle $\varphi_{1}$ from $-\pi / 2$ to $\pi / 2$ (Fig. 5) attends only for the test of the interpolated and calculated data match. In the case of extreme mechanism dimensions, the values could not match and it would be necessary to rise the interpolation polynomial degree [8] - [10].

The $\varphi_{2}$ and $\mathrm{L}_{12}$ coordinates are defined at the start of the simulation (pressed mechanism) for the value $\varphi_{\text {start }}$. The initial values for the calculations noted above are shown in Table 7 .

Initial values of the mechanism variables

Table 7

\begin{tabular}{|l|c|c|c|}
\hline Name & Label & Value & Unit \\
\hline Part 2 initial angle of the centre of gravity & $\varphi_{\text {2start }}$ & 61.298 & Deg \\
\hline Part 2 initial variable distance & $\mathrm{L}_{\text {t2start }}$ & 0.044 & $\mathrm{M}$ \\
\hline
\end{tabular}

The spring force labeled as fon_F $F_{p}(d e f)$ is defined as linear, the output parameter is the $\mathrm{L}_{\mathrm{t} 2}$ value.

\section{Motion equation calculation}

The differential motion equation for the mechanism is defined according to the labels of the parameters defined in the previous text and tables as

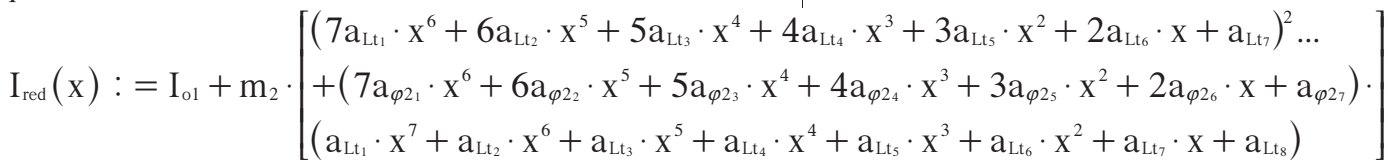

$$
\begin{aligned}
& +\left(\mathrm{I}_{\mathrm{t} 2}+\mathrm{I}_{03}\right) \cdot\left(7 \mathrm{a}_{\varphi 2_{1}} \cdot \mathrm{x}^{6}+6 \mathrm{a}_{\varphi 2_{2}} \cdot \mathrm{x}^{5}+5 \mathrm{a}_{\varphi 2_{3}} \cdot \mathrm{x}^{4}+4 \mathrm{a}_{\varphi 2_{4}} \cdot \mathrm{x}^{3}+3 \mathrm{a}_{\varphi 2_{5}} \cdot \mathrm{x}^{2}+2 \mathrm{a}_{\varphi 2_{6}} \cdot \mathrm{x}+\mathrm{a}_{\varphi 2_{7}}\right)^{2}
\end{aligned}
$$

Reduced forces are labeled as $\mathrm{F}_{\text {Pred }}$ appertaining the spring, $\mathrm{F}_{\mathrm{k}}$ appertaining the contact and $\mathrm{F}_{\mathrm{TR}}$ appertaining the damping.

The motion equation solution leads to the output of the coordinate $\varphi_{1}$ - its angular velocity $d \varphi_{1}$ and $\varphi_{1}$ angle. If the solution failed, it would be necessary to change the solver type (Mathcad "Odesolve" button - ADAMS, FIXED, ...).

The creation of $\mathrm{N}_{t}$ values for the simulation time 0 - tend $\left(\varphi_{1}\right.$, $\left.d \varphi_{1}, d d \varphi_{1}\right)$ is defined with the help of the tt parameter - the time interval vector from 0 to $t_{\text {end }}$ divided to $\mathrm{N}_{\mathrm{t}}$ values.

\section{Contact force simulation results}

The resulting contact force - the main goal of the complex tension mechanism simulation is shown in Fig. 6. The contact force peak value of $284.14 \mathrm{~N}$ was reached in $0.09 \mathrm{~s}$.

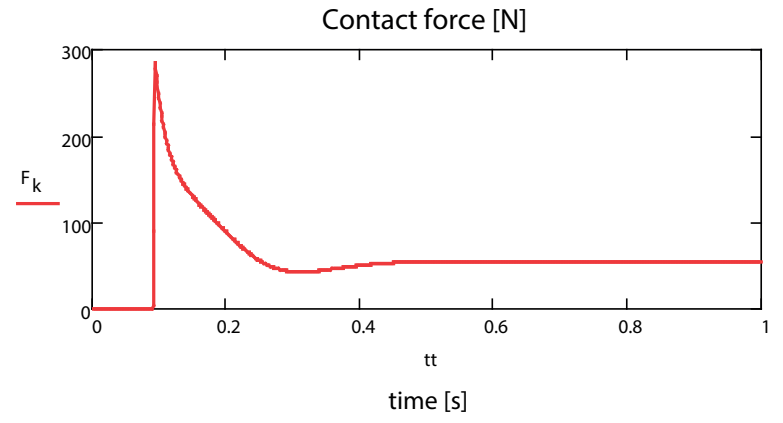

Fig. 6 Tension mechanism contact force calculation result (Source: authors) 


\section{COMMNICOIIONS}

\section{Conclusion}

The mathematical model of the tension mechanism working by a spring motion generation and contacting a rigid body at the end of the motion was built considering the main problem of the analysis - the moment when the mechanism reaches its end position and contacts the frame rigid body with one of its components. It was necessary to use the right model of the friction and contact properties and to calculate the mechanism coordinates via the interpolation polynomial of the 7-th degree. The result of the simulation was the definition of the peak contact force between the mechanism component and the frame rigid body.

\section{References}

[1] DEKYS, V., BRONCEK, J.: Measuring Strain of the Lattice Towers, Communications - Scientific Letters of the University of Zilina, vol. 14, No. 3, 2012, 39-42. ISSN 1335-4205.

[2] DROZDZIEL, P., KRZYWONOS, L.: The Estimation of the Reliability of the First Daily Diesel Engine Start-up During its Operation in the Vehicle, Eksploatacja i Niezawodnosc - Maintenance and Reliability 1(41), 2009, 4-10, ISSN 1507-2711.

[3] HRCEK, S., KOHAR, R., MEDVECKY, S.: Determination on the Maximum Roller Bearing Load with Regards to Durability there of using FEM Analysis. Communications - Scientific Letters of the University of Zilina, vol. 14, No. 3, 2012, 55-61, ISSN 1335-4205.

[4] HRCEK, S., KRAUS, V., KOHAR, R., MEDVECKY, S., LEHOCKY, P.: Construction of a Bearing Testing Apparatus to Assess Lifetime of Large-scale Bearings. Communications - Scientific Letters of the University of Zilina, vol. 11, No. 2, 2009, 57-64, ISSN 1335-4205.

[5] BRUMERCIK, F., KOCUR, R., PAZICAN, M., LUKAC, M.: Differential Hydro-mechanical Transmissions with Hydrostatic Units. Communications - Scientific Letters of the University of Zilina, vol. 7, No. 1, 2005, pp. 49-53, ISSN 1335-4205.

[6] WU, D., YAO, J., LI, H., QIAN, B.: Control Strategy for Hydro-mechanical Differential Turning System of Tracked Vehicles, Nongye Gongcheng Xuebao / Transactions of the Chinese Society of Agricultural Engineering, vol. 28, No. 8, 2012, 78-83, ISSN 10026819.

[7] KOHAR, R., HRCEK, S., MEDVECKY, S.: Usage of Dynamic Analysis to Determine Force Interactions between Components of Rolling Bearings. Communications - Scientific Letters of the University of Zilina. vol. 14, No. 3, 2012, 62-67, ISSN 1335-4205.

[8] KUCERA, L., LUKAC, M., JURAK, L., BRUMERCIK, F.: Hydromechanical Automatic Transmission, Communications Scientific Letters of the University of Zilina, vol. 11, No. 2, 2009, 33-35, ISSN 1335-4205.

[9] LEHOCKY, P., KOHAR, R., HRCEK, S., PODHORSKY, J., SURMOVA, B., MEDVECKY, S., HRCEKOVA, A.: Automative Unwinding of Waste Paper from Reel Spools. Communications - Scientific Letters of the University of Zilina, vol. 9, No. 1, 2007, 60-66, ISSN 1335-4205.

[10] WANG, G., ZHU, S., SHI, L., TAO, H., VANTHINH, N.: Experimental Optimization on Shift Control of Hydraulic Mechanical Continuously Variable Transmission for Tractor, Nongye Gongcheng Xuebao / Transactions of the Chinese Society of Agricultural Engineering, vol. 29, No. 18, 51-59, 2013, ISSN 1002-6819. 